\section{SCHEME: An interactive FORTRAN program to analyze and simulate group decision data}

\author{
DENNIS H. NAGAO and VERLIN B. HINSZ \\ University of Ilinois, Champaign, Illinois 61820
}

SCHEME is an interactive FORTRAN program designed to analyze and simulate group decision data using social decision scheme (SDS) theory (Davis, 1973). In general, the theory assumes that group members arrive at a decision through the use of some explicit or implicit decision rule, or SDS, which may often be characterized by a familiar label (e.g., majority wins, averaging, etc.). The general stochastic model can operate on any distribution of individual preferences using any SDS to produce a theoretical distribution of group decisions (where the groups are assumed to have been randomly formed). One measure of the adequacy of the hypothesized social decision rule as a model of group decision making may be obtained by comparing the predicted group distribution with an observed group distribution. This use of the theory is referred to as model testing (Kerr, Stasser, \& Davis, 1979). Recent applications of the theory in this manner have included investigations of mock-jury decision processes (Davis, Kerr, Atkin, Holt, \& Meek, 1975; Davis, Spitzer, Nagao, \& Stasser, 1978; Kerr, Atkin, Stasser, Meek, Holt, \& Davis, 1976), group problem solving processes (Laughlin, 1980; Laughlin, Kerr, Davis, Halff, \& Marciniak, 1975), and group decisions concerning attitudinal issues (Kerr, Davis, Meek, \& Rissman, 1975).

The theory may also be used to simulate the effects of group size, decision rule, or different distributions of individual preferences on the distribution of group decisions. Hence, the theory allows us to examine hypothetical but specific questions concerning the preceding factors for which available data bases may be inadequate or nonexistent. This approach is exemplified by Vollrath and Davis (1979), who used SDS theory to assess some of the potential consequences of legislation proposing changes in the size and decision rule employed by federal grand juries. Further examples are provided by Davis (1980) and Nagao and Davis (in press). (See Davis, 1980, especially for a more detailed discussion of formal theories and their potential for social engineering applications.)

SCHEME performs both model testing and simulation SDS analyses for any of a number of particular decision

The development of this program was supported by Grant BNS-7715216 from the National Science Foundation to the University of Illinois, James $\mathbf{H}$. Davis, principal investigator. The authors would like to thank Norbert Kerr, Garold Stasser, Marilyn Henninger, and Craig Spitzer for contributing various subroutines that were incorporated into SCHEME. We would also like to thank James H. Davis and R. Scott Tindale for their comments on a previous draft. rules in which the investigator is confronted with $n$ distinguishable response alternatives preferred by $r$ indistinguishable persons. As such, SCHEME is applicable to the general class of combinatoric problems sometimes called "occupancy problems" (e.g., Feller, 1957), which are often encountered in group decision and social choice research.

\section{SOCIAL DECISION SCHEME THEORY}

A more formal description of the general SDS model follows. For some set of $n$ mutually exclusive and exhaustive alternatives $A_{1}, A_{2}, \ldots, A_{n}$, let the preferences of individuals be described by the probability distribution $\mathrm{p}_{1}, \mathrm{p}_{2}, \ldots, \mathrm{p}_{\mathrm{n}}$ across the alternatives. For a group of $\mathrm{r}$ individuals, the internal distribution of preferences may be represented by the occupancy numbers $r_{1}, r_{2}, \ldots, r_{n}$, where

$$
\sum_{i=1}^{n} r_{i}=r \text {. }
$$

For a given $\mathrm{r}$ and $\mathrm{n}$, the $\mathrm{m}$ distinguishable distributions of member preferences within a group are given by

$$
m=\left(\begin{array}{c}
n+r-1 \\
r
\end{array}\right) .
$$

The $m$ sets of occupancy numbers are the solutions to $r_{1}+r_{2}+\ldots+r_{n}=r$. The probability, $\pi_{\mathfrak{j}}$, that the group members arrange themselves according to the ith distribution may be estimated directly in some research applications by counting the relative frequency, $\hat{\pi}_{\mathfrak{i}}$, with which the ith array occurs. But in other instances, $\pi_{i}$ must be estimated indirectly by substituting the estimates $\left(\hat{p}_{1}, \hat{p}_{2}, \ldots, \hat{p}_{n}\right)$ from a sample of individuals in the expression

$$
\pi_{i}=\left(\begin{array}{c}
r \\
r_{1}, r_{2}, \ldots, r_{n}
\end{array}\right) p_{1}^{r_{1}} p_{2}{ }^{r_{2}} \ldots p_{n}{ }^{r_{n}}
$$

the general term of the multinomial expansion.

The conditional probability, $\mathrm{d}_{\mathrm{ij}}$, is defined as the probability of the group's choosing the jth response alternative given the ith distinguishable distribution. The SDS, which may be represented as an $m$ by $n$ stochastic matrix, $D$, defines the values of $d_{i j}$ for all $\mathrm{i}=1,2, \ldots, \mathrm{m}, \mathrm{j}=1,2, \ldots, \mathrm{n}$, and

$$
\sum_{j=1}^{n}\left(d_{i j}\right)=1.0 \text {. }
$$

Hence, the SDS may be regarded as a means of operating on the row vector $\pi=\left(\pi_{1}, \pi_{2}, \ldots, \pi_{n}\right)$ to yield the predicted probability distribution $P=\left(P_{1}, P_{2}, \ldots, P_{n}\right)$ of group choices [i.e., $\left(P_{1}, P_{2}, \ldots, P_{n}\right)=\pi D$ ] . For a more comprehensive description, see Davis, 1973; Stasser, Kerr, \& Davis, 1980). 


\section{THE FORTRAN PROGRAM}

SCHEME is written in CDC FORTRAN Extended Version 4 for use in timesharing mode on a CDC 170 under the network operating system (NOS). The program, however, may be modified with relative ease to be compatible with nearly any FORTRAN compiler. ${ }^{1}$ The program does not use the matrix representation of a SDS described by Davis (1973), but instead, it embodies each rule as an algorithm that operates on the ith distinguishable distribution, partitioning its associated $\pi_{i}$ appropriately. These SDSs are embodied in the program as separate subroutines. Hence, the user may easily add routines as needed.

There are two sets of SDSs available to the user in this version of SCHEME: "jury" and "response scale." The former, as the name implies, are decision rules that are rationalized by analogy with petit juries (e.g., $2 / 3$ majority, otherwise hung). Selection of this set automatically sets the number of alternatives (i.e., guilty, not guilty, and hung). However, this set may be useful with other applications requiring nominal response categories. The response scale set contains more general decision rules (e.g., majority-equiprobability: simple majority "rules" when it exists; equiprobability applies if there is no simple majority) rationalized by analogy with tasks allowing an ordered set of response alternatives. In the latter case, the number of alternatives may range from 2 through 11 , inclusive.

SCHEME also allows the user, in both model testing and simulation modes, to explore the implications of sampling from multiple populations with different probabilities (see Davis, 1980, for a detailed discussion of this technique). The user may specify up to nine distributions of individual preferences (assuming a constant number of alternatives) to represent different populations. If this option is selected (i.e., more than one population is specified), the user must also specify the probability of sampling from each population, with the constraint that the sampling probabilities must sum to 1 .

Upon execution, SCHEME will query the user for the information necessary to conduct the desired analyses. To respond, the user need only type in the appropriate information at the terminal. Due to the interactive nature of the program, little computer expertise is needed. SCHEME also allows the user to conduct multiple sets of analyses per execution of the program.

\section{Input and Output}

Model Testing Mode. In model testing mode, SCHEME requires the user to provide the following information: (1) group size, (2) number of alternatives, (3) frequency distribution of individual responses over the alternatives, and (4) frequency distribution of group responses over the alternatives. In addition, the user must specify which SDS set (jury or response scale) as well as which SDSs within that set are to be executed. (Currently, there are 15 SDSs in each set.)

As options, SCHEME allows the user (1) to provide a label (up to 80 characters) for each analysis set conducted, (2) to sample from more than one subject population (the user must specify the various population probability distributions), (3) to directly input or calculate (from each group's members initial prediscussion opinions) the observed relative frequency of each distinguishable distribution of member preferences (the former being restricted, however, only to the jury SDSs), and (4) to request a graph of the observed and predicted group distributions for each SDS executed.

For each SDS executed within model testing mode, the observed individual, group, and theoretical distributions are printed, as well as the results of a KomogorovSmirnov one-sample goodness-of-fit test. If cued as an option, relative frequency plots of the obtained and predicted group distributions, for each SDS executed, are also printed.

Simulation Mode. For each analysis set conducted in simulation mode, SCHEME requires the user to set the number of response alternatives and select the SDSs to be executed. However, the user may now specify up to nine different group sizes and either nine distributions of individual preferences or nine distributions of population sampling probabilities. Given the preceding information, SCHEME will systematically calculate, for each combination of group size, individual distribution, and SDS, the relevant theoretical group distributions.

For each analysis set conducted in simulation mode, SCHEME outputs a header line that specifies the number of group sizes, individual distributions, SDSs, and alternatives involved in the analysis. Immediately following are printed the distribution(s) of individual preferences over the alternatives, followed by the predicted group distributions. In addition, for each of the predicted group distributions, the group size, number corresponding to the individual distribution used to estimate parameters, and number of the SDS that generated the predictions are printed. In this form, the output may easily be read by other computer programs for further analysis or exposition (e.g., graphing of results).

\section{PROGRAM AVAILABILITY}

A source listing of the program, user's manual, and sample input and output may be obtained free of charge by writing to either author at the Department of Psychology, University of Illinois, Champaign, Illinois 61820 .

\section{REFERENCES}

DAvis, J. H. Group decision and social interaction: A theory of social decision schemes. Psychological Review, 1973, 80, 97-125.

DAvis, J. H. Ciroup decision and procedural justice. In M. Fishbein (F(1). Progeress in social psychology. Hillsdale, N.J: Erlbaum, 1980 (). 
Davis, J. H., Kerr, N. L., Atkin, R. S., Holt, R., \& Meek, D. The decision processes of 6- and 12-person juries assigned unanimous and $2 / 3$ majority rules. Journal of Personality and Social Psychology, 1975, 3, 1-14.

Davis, J. H., Spitzer, C. E., Nagao, D. H., \& Stasser, G. The nature of bias in social decisions by individuals and groups -An example from mock juries. In H. Brandstatter, J. H. Davis, \& H. Schuler (Eds.), Dynamics of group decisions. Beverly Hills, Calif: Sage, 1978.

FELLER, W. An introduction to probability theory and its applications (Vol. 1). New York: Wiley, 1957.

Kern, N. L., Atkin, R. S., Stasser, G., Meek, D., Holt, R. W., \& DAvis, J. H. Guilt beyond a reasonable doubt: Effects of concept definition and assigned decision rule on the judgments of mock jurors. Journal of Personality and Social Psychology, 1976, 34, 282-294.

Kerr, N. L., Davis, J. H., Meek, D., \& Rissman, A. K. Group position as a function of member attitudes: Choice shift effects from the perspective of social decision scheme theory. Journal of Personality and Social Psychology, 1975, 31, 574-593.

Kerr, N. L., Stasser, G., \& Davis, J. H. Model testing, model fitting and social decision schemes. Organizational Behavior and Human Performance, 1979, 23, 399-410.

LaUghlin, P. R. Social combination processes of cooperative problem-solving groups on verbal intellective tasks. In $\mathbf{M}$. Fishbein (Ed.), Progress in social psychology. Hillsdale, N.J: Erlbaum, 1980.
Laughlin, P. R., Kerr, N. L., Davis, J. H., Halff, H. M. \& MarciniaK, K. A. Group size, member ability, and social decision schemes on an intellective task. Journal of Personality and Social Psychology, 1975, 31, 522-535.

Nagao, D. H., \& Davis, J. H. Some implications of temporal drift in social parameters. Journal of Experimental Social Psychology, in press.

SIEGEL, S. Nonparametric statistics for the behavioral sciences. New York: McGraw-Hill, 1956.

Stasser, G., KerR, N. L., \& Davis, J. H. Influence processes in decision-making groups: A modeling approach. In P. Paulus (Ed.), Psychology of group influence. Hillsdale, N.J: Erlbaum, 1980.

Vollrath, D. A., \& Davis, J. H. Evaluating proposals for social change with minimal data: An example from grand jury reform. Law and Human Behavior, 1979, 3, 121-134.

\section{NOTE}

1. A source listing of a CDC 170 and an IBM 360 FORTRAN batch version of SCHEME requiring only standard peripheral hardware (i.e., card reader and printer) is also available from the authors.

(Accepted for publication August 13, 1980.)

\section{ERRATUM}

Gorman, B. S., \& Primavera, L. H. BACKSTEP: A simple program for backward-selection multiple regression. Behavior Research Methods \& Instrumentation, 1980, 12(3), 391-392. Page 391: Equation 2 that appeared in Column 1 was incorrect. The correct equation is shown below.

$$
\beta_{p}=-q_{p c} / q_{c c} .
$$

